\title{
VI答 93
}

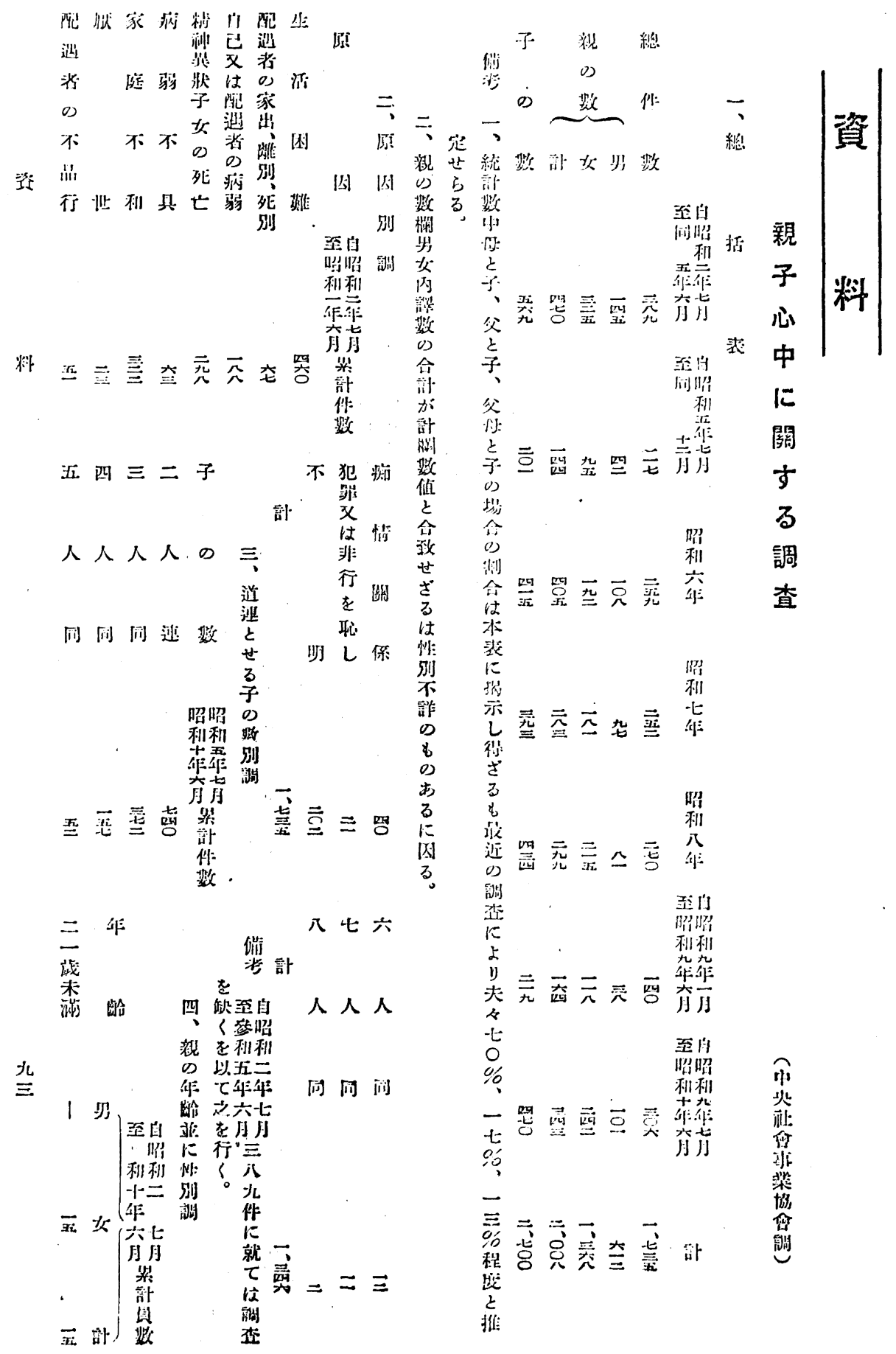


正入七六五四三二一而

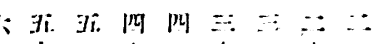

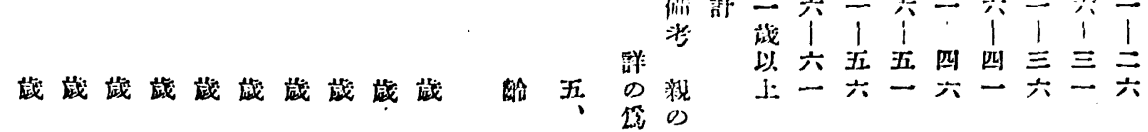
子. 冰全

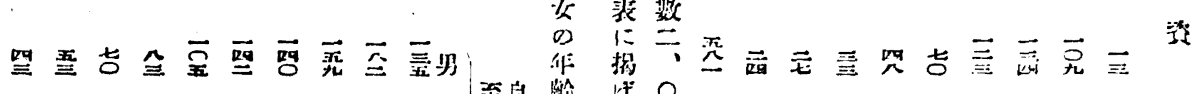

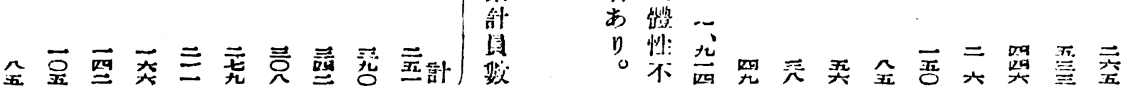

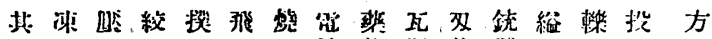
湖物斯物器

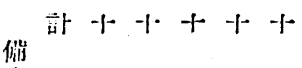
にに心 に

苋伍四三:-

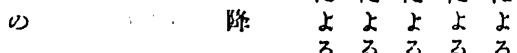

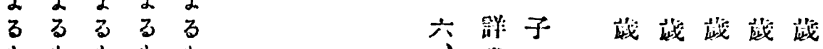

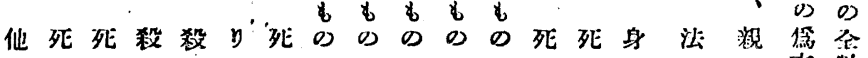

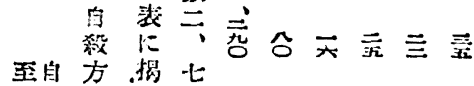

$$
\begin{aligned}
& \text { 热炤法将。 } \\
& \text { 利利别吉 } 0 \\
& x=\text { 名 }
\end{aligned}
$$

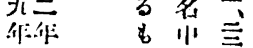

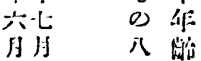

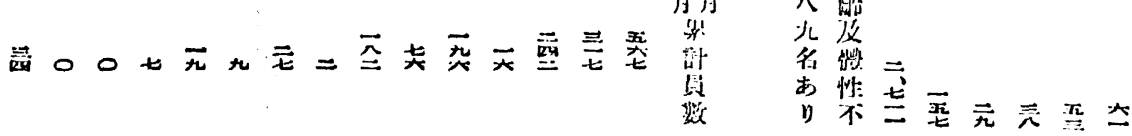
儿文

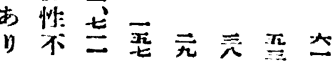

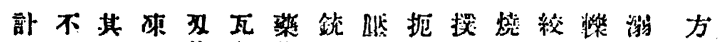
部不
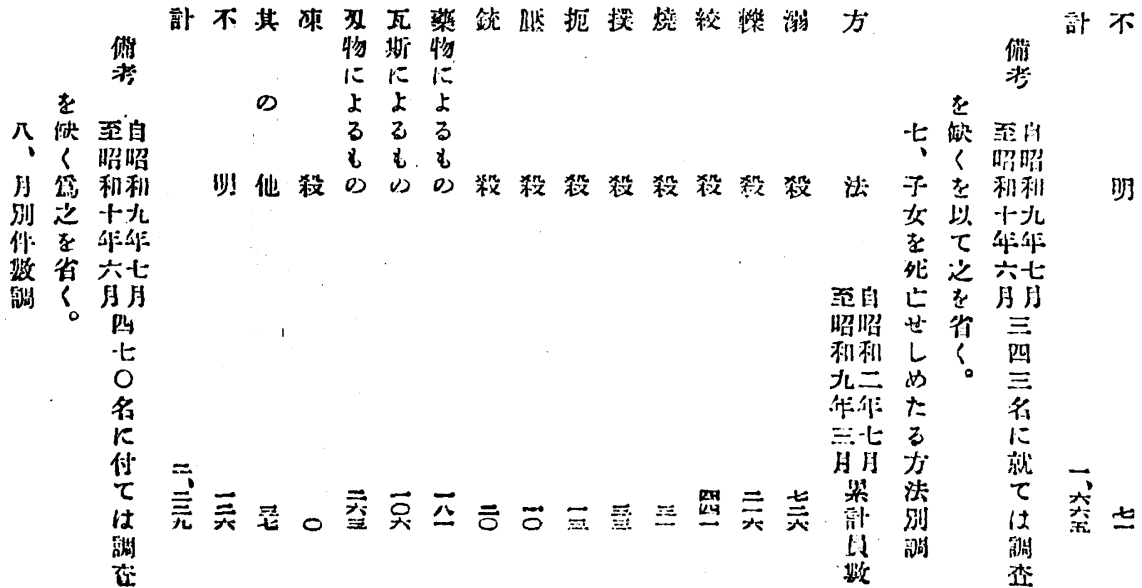

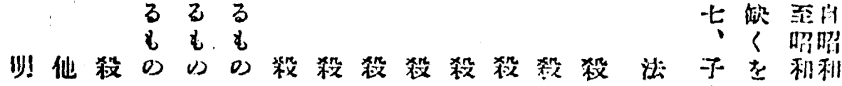

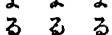

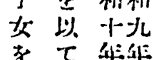

死方六比

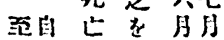

昭䎏世省三

和和し了四

光分界。”

名

H月

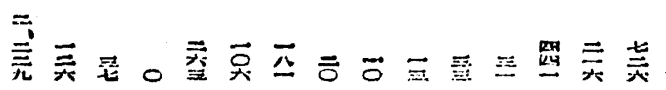

梁

站

杂

t5 
V1 惩 9.5

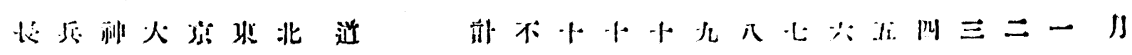

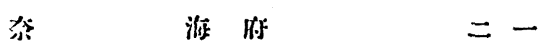

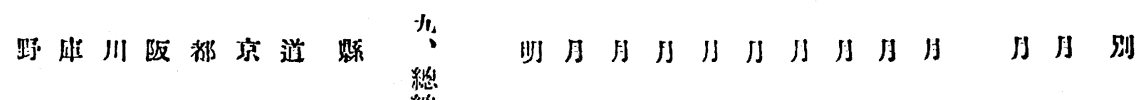

资

料

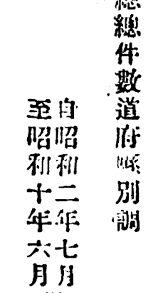

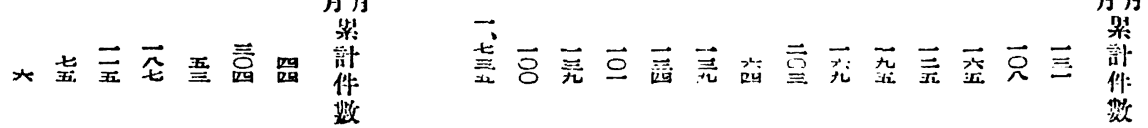

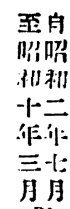

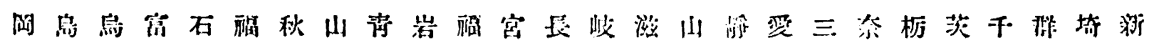

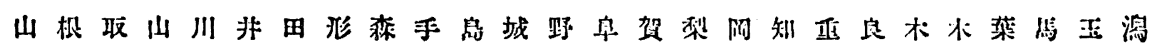

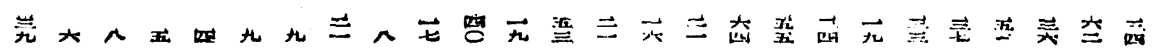

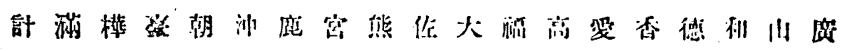
兒

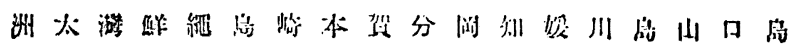

光

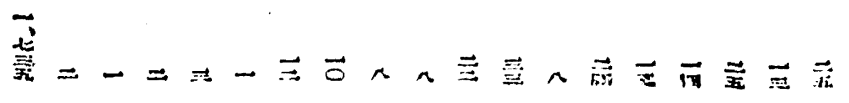




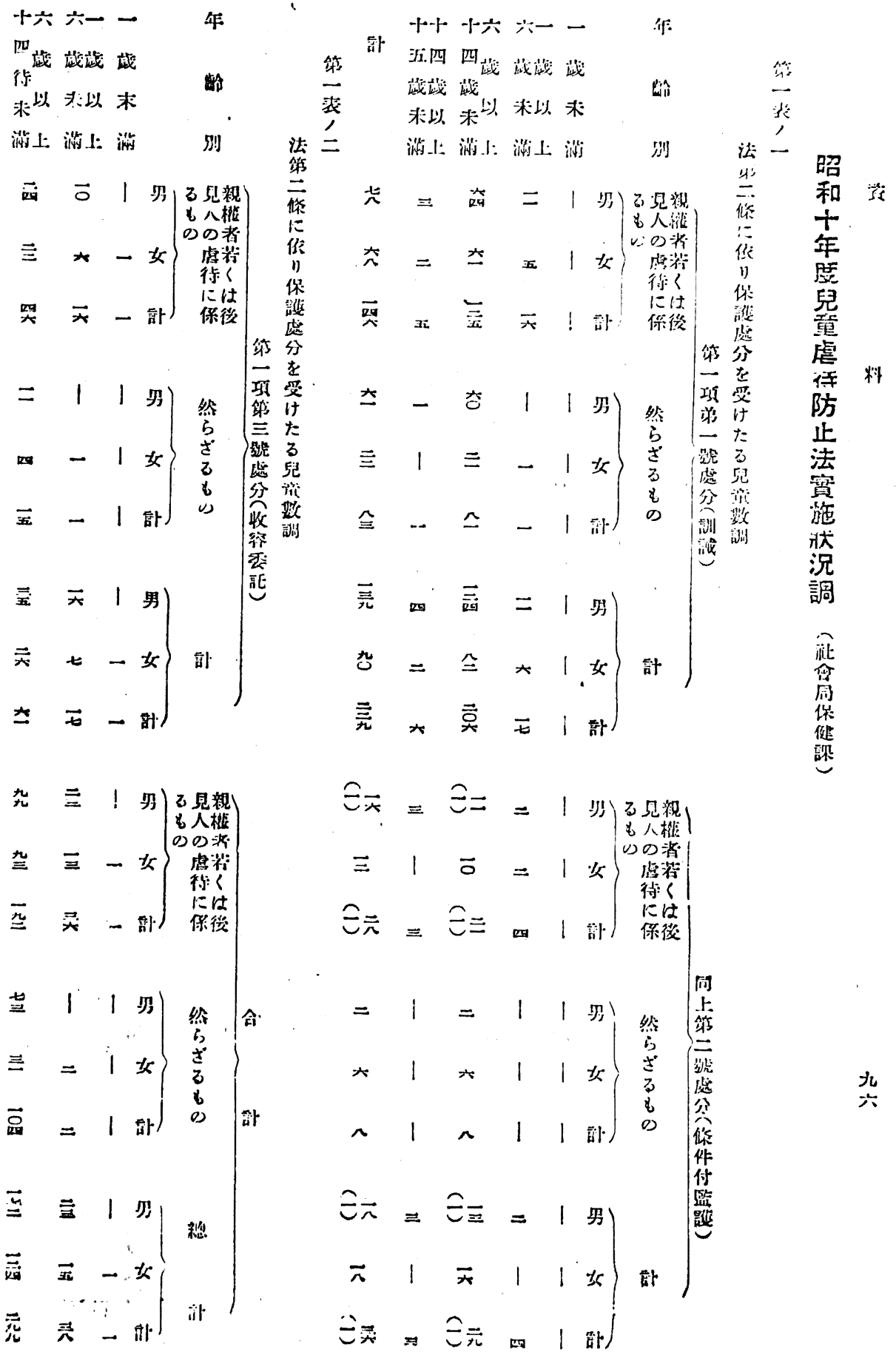




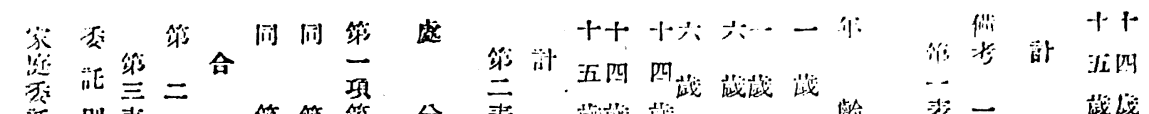

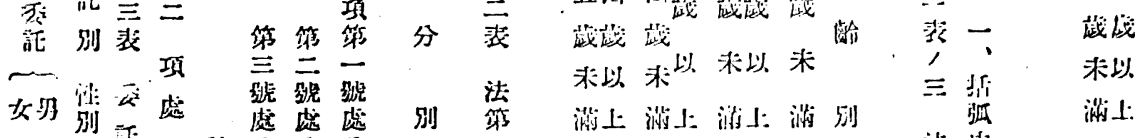

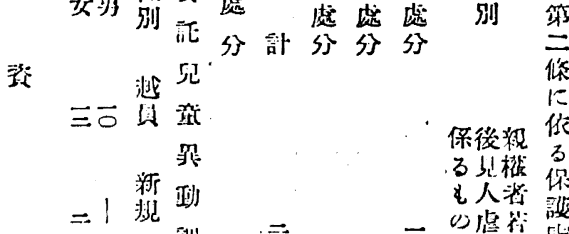

$$
\begin{aligned}
& \text { 泣陌 } \\
& \text { 第焉致 } \\
& \text { 條繁: }
\end{aligned}
$$

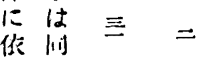

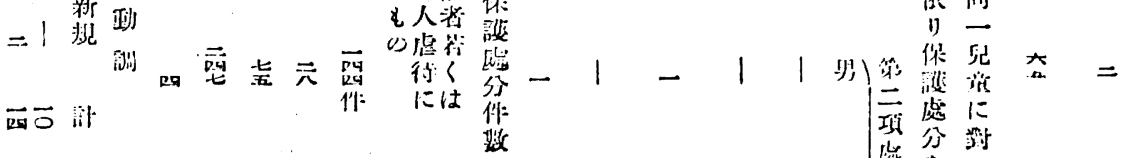

$$
\begin{aligned}
& \text { =ー些 } \\
& 1 \mid \text { 多 = 品可へ色 } \\
& \begin{array}{l}
\text { 然 } \\
\text { さे } \\
\vdots \\
\text { ๖ } \\
0
\end{array} \\
& \text { =- के }
\end{aligned}
$$

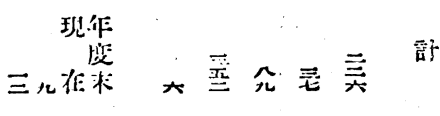

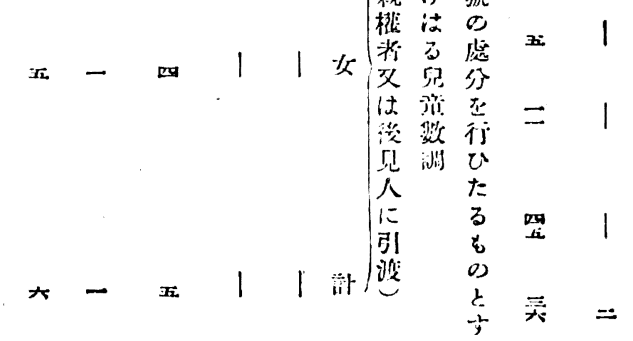

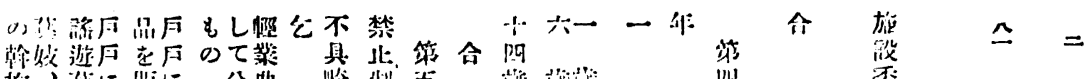

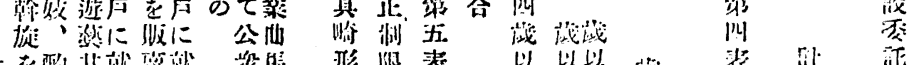

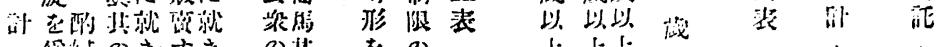

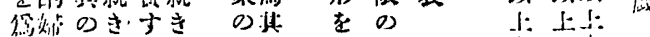

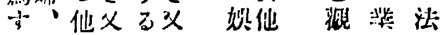

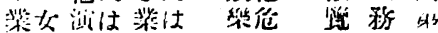

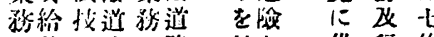

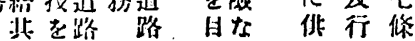

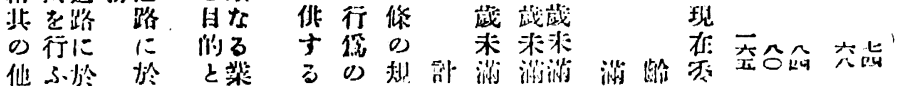

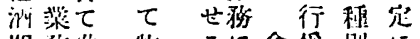

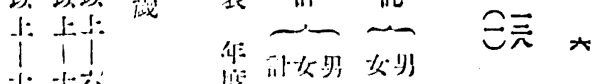

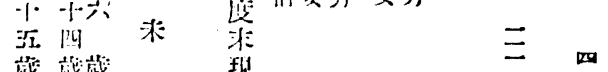

こ荘

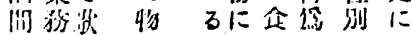

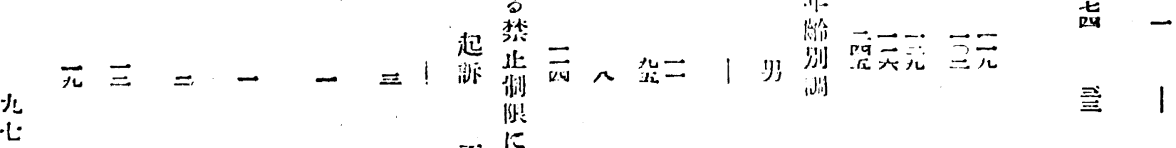

$$
\begin{aligned}
& \text { 不に }
\end{aligned}
$$

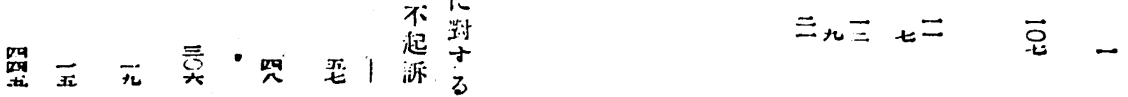

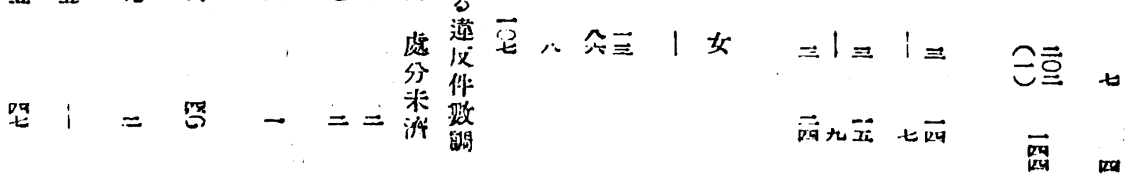

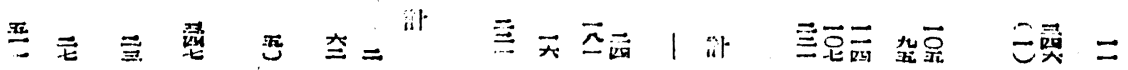

